Florida International University FIU Digital Commons

$3-28-2012$

\title{
The Influence of Parental Verbal Aggression on Hispanic College Women's Use of Verbal Aggression in Romantic Relationships
}

Laura A. Oramas

Florida International University, loram001@fiu.edu

DOI: $10.25148 /$ etd.FI12041902

Follow this and additional works at: https://digitalcommons.fiu.edu/etd

\section{Recommended Citation}

Oramas, Laura A., "The Influence of Parental Verbal Aggression on Hispanic College Women's Use of Verbal Aggression in Romantic Relationships" (2012). FIU Electronic Theses and Dissertations. 566.

https://digitalcommons.fiu.edu/etd/566 


\title{
FLORIDA INTERNATIONAL UNIVERSITY \\ Miami, Florida
}

THE INFLUENCE OF PARENTAL VERBAL AGGRESSION ON HISPANIC COLLEGE WOMEN'S USE OF VERBAL AGGRESSION IN ROMANTIC

RELATIONSHIPS

\author{
A thesis submitted in partial fulfillment of the \\ requirements for the degree of \\ MASTER OF SCIENCE \\ in \\ PSYCHOLOGY \\ by \\ Laura A. Oramas
}

2012 


\section{To: Dean Kenneth Furton}

College of Arts and Sciences

This thesis, written by Laura A. Oramas, and entitled The Influence of Parental Verbal Aggression on Hispanic College Women's Use of Verbal Aggression in Romantic Relationships, having been approved in respect to style and intellectual content, is referred to you for judgment.

We have read this thesis and recommend that it be approved.

\section{Mary Levitt}

William M. Kurtines

Dionne Stephens, Major Professor

Date of Defense: March 28, 2012

The thesis of Laura A. Oramas is approved.

\begin{tabular}{r} 
Dean Kenneth Furton \\
College of Arts and Sciences \\
\hline Dean Lakshmi N. Reddi \\
University Graduate School
\end{tabular}

Florida International University, 2012 


\section{DEDICATION}

This thesis is dedicated to my family and friends who have supported and encouraged me throughout every stage of its development. 


\section{ACKNOWLEDGMENTS}

I would like to take this opportunity to thank those who have contributed to the successful completion of this thesis. First and foremost I would like to thank my mentor, Dr. Dionne Stephens for her patience and guidance through every step of the process. From the formative stages of this project to the final draft, I am deeply grateful for the guidance and support she has provided in carrying it out. Further, the incredible opportunity she has given me to develop my own research project and interests has been invaluable to my professional development.

I would also like to thank Dr. Melody Whiddon for her advice and support during some of the most crucial years of my academic career to date. From applying to graduate school to assisting me in the final stages of this thesis, she has been there every step of the way to support and encourage me, and for that I am tremendously grateful to her. Moreover, her assistance with using Structural Equation Modeling to carry out the analyses of this project was invaluable to its successful completion.

Further, I would like to thank my committee members, Dr. Mary Levitt and Dr. William Kurtines, for believing in my research and pushing me to challenge myself academically and professionally. Their guidance was a great influence on the development of this thesis.

Finally, this thesis would not have been possible without the undergraduate assistants of the Health Disparities and Cultural Identities Lab, such as Angelica Lopez, Adriana Yanquez, and Aida Custode, who spent countless hours helping to enter my data, and who always went above and beyond what was expected of them to ensure that it was accurate and complete in a timely manner. 


\begin{abstract}
OF THE THESIS
THE INFLUENCE OF PARENTAL VERBAL AGGRESSION ON HISPANIC COLLEGE WOMEN'S USE OF VERBAL AGGRESSION IN ROMANTIC RELATIONSHIPS

by
\end{abstract}

Laura A. Oramas

Florida International University, 2012

Miami, Florida

Professor Dionne Stephens, Major Professor

The thesis investigates the relation between interparental verbal aggression, parent-daughter verbal aggression, and verbal aggression in female Hispanic college student's dating relationships $(\mathrm{N}=599)$. This study builds on previous work that has been conducted to provide evidence of the influence of parental verbal conflict strategies on college women's own experiences with and use of verbal aggression (Black, Sussman, \& Unger, 2010; Luthra \& Gidycz, 2006; Martin, 1990; Palazzolo, Roberto, \& Babin, 2010; Riggs \& O'Leary, 1996). However, this is the first study that has specifically examined this phenomenon within a Hispanic population.

Results showed that mothers' high levels of verbal conflict with fathers were predictive of having high levels of verbal conflicts with their daughters. This in turn, predicted daughters' use of verbal conflict with their intimate partner. Similarly, fathers' high levels of verbal conflict with mothers were predictive of having high levels of verbal conflicts with their daughters. However, this was not found to be predictive of daughters' use of verbal conflict with their intimate partner. 


\section{TABLE OF CONTENTS}

CHAPTER

PAGE

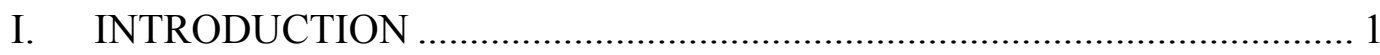

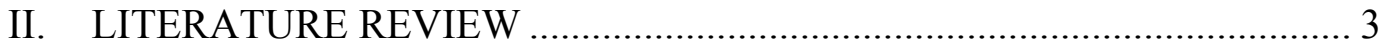

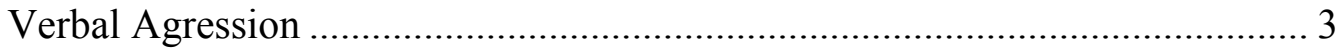

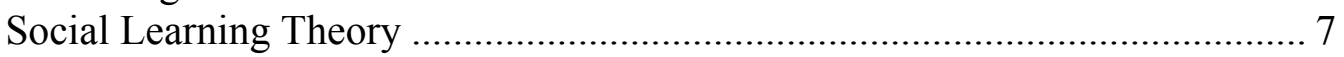

Interparental Verbal Agression ................................................................. 9

Parent- Daughter Verbal Agression .............................................................. 12

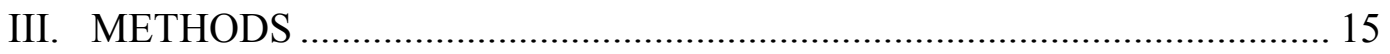

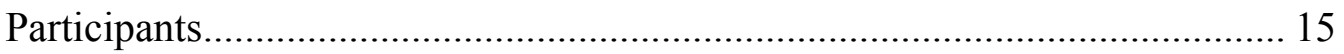

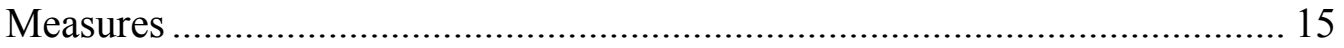

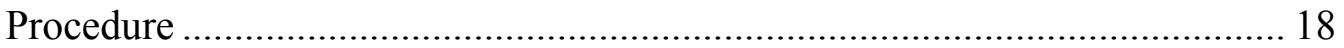

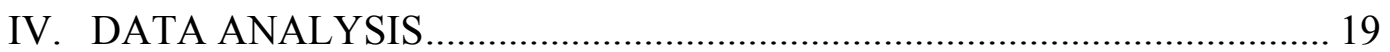

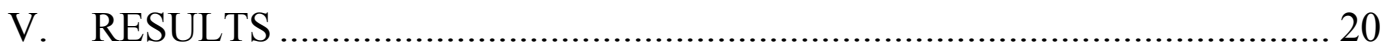

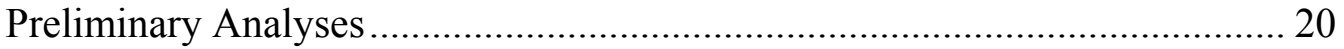

Primary Analyses ................................................................................ 20

Mother- Daughter Verbal Agression .............................................................. 22

Father- Daughter Verbal Agression .................................................................. 22

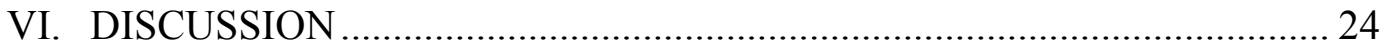

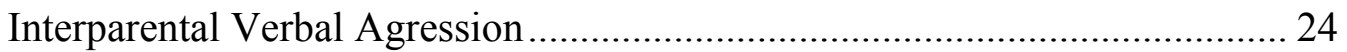

Mother- Daughter Verbal Agression ........................................................... 25

Father- Daughter Verbal Agression ............................................................. 26

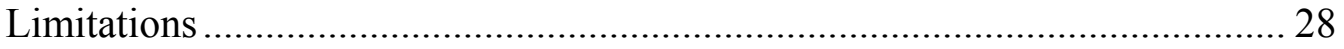

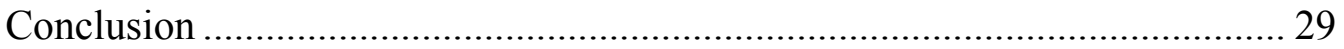

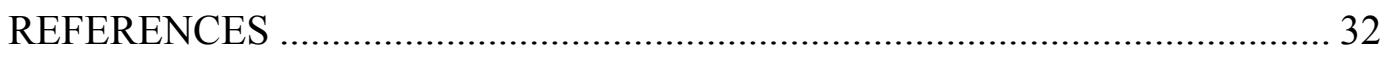

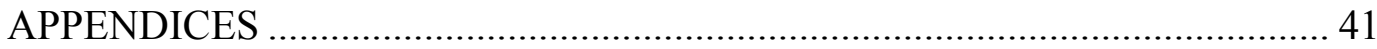




\section{INTRODUCTION}

Research has shown that verbal aggression is one of the most common forms of intimate partner violence (IPV) used by college students. Deemed a significant public health concern, verbal aggression is defined as verbal communications intended to cause psychological pain to another person, or a communication perceived as having that intent (Infante, 1995; Schumacher \& Leonard, 2005). Examples include name calling or nasty remarks (active, verbal), slamming a door or smashing something (active, nonverbal) and stony silence or sulking (passive, nonverbal) (Infante, 1995). It is estimated that 20 to $25 \%$ of women experience some form of verbal aggression or coercion in their current romantic relationships (e.g., Hines, 2007; Katz, Washington, Kuffel, \& Brown, 2006; Muñoz-Rivas, Graña, O'Leary, \& González, 2009). Further, women are more likely to use verbally aggressive tactics than engage in other confrontational approaches with their male partners (Dowd, Leisring \& Rosenbaum, 2005; Harned, 2001; Straus \& Sweet, 1992).

As the most proximal influence on their children, parents' interactions play a primary role in preparing daughters for intimate relationships. Recent findings provide evidence that understanding the verbal strategies used in interparental conflicts may be effective in understanding daughters' utilization and acceptance of verbal aggression in their own intimate relationships (Black, Sussman, \& Unger, 2010; Luthra \& Gidycz, 2006; Martin, 1990; Palazzolo, Roberto, \& Babin, 2010; Riggs \& O’Leary, 1996). How Hispanic $^{1}$ parents interact with each other serves to communicate beliefs about love,

\footnotetext{
${ }^{1}$ I recognize that there is a debate about the use of the terms Hispanic and Latino. However, as the interviews for the present study were conducted in an urban center where the majority of residentsincluding the study participants - primarily self-identify as Hispanic, I use this term in the present paper.
} 
acceptance, trust and intimacy, all of which may have implications for understanding how Hispanic college women learn skills to negotiate conflict in with others.

In the current research, we intend to explore the relationship verbal aggressive styles used in interparental, parent- daughter, and daughters' intimate relationship. The focus is on daughters' conflict style because of the specific risk children who witness forms of IPV face when in their own intimate relationships. We expect that Hispanic college women who witness high levels of verbal aggression in their parents' relationships will utilize these same tactics in their own intimate relationship conflicts. The findings from this study contribute to our knowledge in the area of IPV and Hispanic college students, which has been understudied. Further, given the detrimental consequences that verbal aggression, these results will increase our ability to address victimization and improve relationship outcomes in this population. 


\section{LITERATURE REVIEW}

\section{Verbal Aggression}

Over the last several decades, IPV has emerged as a significant public health issue. However, until recently most dating violence research has focused on physical forms of IPV, which is problematic since research indicates that verbal aggression is more prevalent than physical aggression in women's lives. In a study of 1,000 women 15 years of age or older, $36 \%$ had experienced emotional abuse while growing up; $43 \%$ had experienced some form of abuse as children or adolescents; 39\% reported experiencing emotional abuse in a relationship in the past five years (Women's College Hospital, 1995). College-age women in America represent a particularly vulnerable group for intimate partner violence. An average of $80 \%$ of college women believe verbal abuse is a serious issue for their age group, while $25 \%$ have reported having endured repeated verbal abuse in an intimate relationship (e.g., Hines, 2007; Katz \& Myhr, 2008; Katz, Washington, Kuffel, \& Brown, 2006; Muñoz-Rivas, Graña, O'Leary, \& González, 2009). Although the types of abusive tactics used do not differ, the rates of verbal aggression use are higher in racial/ethnic college populations (Muñoz-Rivas, Graña, O'Leary, \& González, 2009). The reasons for this are unknown, in part, because of the lack of research in these areas.

Defining verbal aggression. Verbal aggression is defined as an attack to a person's self-concept, including the use of threats, profanity, yelling, and insults (Infante \& Wigley, 1986). Similarly, the American Professional Society on the Abuse of Children (2000) refers to emotional abuse as psychological maltreatment, a repeated pattern behavior that conveys to the victims that they are worthless, flawed, unloved, unwanted, 
endangered, or only of value in meeting another's needs (Esteban, 2006). Thus verbal abuse has been identified as a distinct form of emotional abuse, and placed it at the core of emotionally abusive behavior (Esteban, 2006; O'Hagan, 1995; Tomison, \& Tucci, 1997).

Prevalence of verbal aggression. Verbally aggressive behaviors have been found to be an extremely common type of IPV used against women, being reported in $20-25 \%$ of women's current romantic relationships (e.g., Hines, 2007; Katz, Washington, Kuffel, \& Brown, 2006; Muñoz-Rivas, Graña, O'Leary, \& González, 2009). Researchers suggest the rates are actually much higher, as these are considered less obvious forms of violence, leading them to be often overlooked or normalized in intimate relationships (Katz, Moore, \& Tkachuk, 2007; Jezl, Molidor, Wright, 1996; Muñoz-Rivas, Graña Gómez, O’Leary, \& González Lozano, 2007). Unlike physical violence, there are no physical marks, or public policies that define boundaries of acceptability, making labeling or recognizing verbal aggression more difficult. When discussing women's perceptions of physical and psychological forms of domestic violence, IPV researcher Liz Kelly concluded, "What is not named is invisible, and in a social sense, nonexistent" (114). Thus, the verbal aggression that may occur in parental interactions is often not acknowledged as a form of "violence" and is instead normalized as part of domestic relationships.

The regularity of verbal aggression combined with its nonviolent nature may make it difficult to identify as abuse, especially within emerging adult populations. However, it is important to note that these aggression tactics are among the most common conflict styles that women use in their own intimate relationships. Findings 
from national surveys (Straus \& Sweet, 1992), the dating violence literature (see Dowd, Leisring, \& Rosenbaum, 2005; Winstok, 2006), and numerous studies of both community and clinical samples show that women are as frequently verbally aggressive toward their male partners as men are to female partners. Straus, Hamby, Boney-McCoy, and Sugarman, (1996) found that women to engage in equal amounts of verbal aggression against their partners, such as name-calling, insulting, sulking, and slamming doors, and throwing things. In fact, $75 \%$ of the women acknowledged at least one such act of aggression in the previous year, with a mean average of 10.3 incidents during that year. Muñoz-Rivas, Graña Gómez, O’Leary, and González Lozano’s (2007) study with Spanish college students similarly found that women are substantially more likely to utilize verbal aggression. The rates of use are so pervasive in dating relationships that research suggests that verbal aggression is often regarded as a normalized element of dating (Jezl, Molidor, Wright, 1996; Muñoz-Rivas, Graña Gómez, O’Leary, \& González Lozano, 2007).

Consequences of verbal aggression. Despite the normalization of these behaviors, the consequences of verbal aggression have a significant impact on the physical and psychological well-being of individuals. The effects of verbal aggression can range from temporary feelings of embarrassment, anger, irritation, etc. to more serious damage to one's self-concept (Infante, Trebing, Shepherd \& Seeds, 1984). For example, victims of verbal aggression have been found to experience higher levels of physical and psychological symptomology. Research has noted that victims of verbal aggression are at an increased risk of physical symptomology such as irritable bowel syndrome, chronic pain, and migraine headaches (Coker, Smith, Bethea, King, and 
McKeown, 2000). Post-Traumatic Stress Disorder, anxiety, depression, and suicidal ideation (Coker et al., 2002; Hegarty, Gunn, Chondros, \& Small, 2004; Pico-Alfonso et al., 2006) have also been noted among those who have been victims of verbal aggression. These, in turn, significantly increases the likelihood of the victims of verbal aggression engaging in heavy alcohol and drug use (Coker et al., 2002) and attempted suicide (PicoAlfonso et al., 2006). Although there are no studies that specifically consider the implication of verbal aggression among Hispanic populations, research on general IPV process have shown that Hispanic IPV victims had significantly greater trauma-related symptoms, depression, lower social and personal self-esteem, and were less likely to make global attributions for positive events than were other women (see Edelson, Hokoda \& Ramos- Lira, 2007).

It is also important to consider the influence of these conflict tactics on long term conflict patterns in intimate relationships. Prior research has shown that those who experience or witness verbal aggression in significant relationships (i.e., familial), are also more likely to use this conflict tactic in intimate relationships (Black, Sussman, \& Unger, 2010; Martin, 1990; Murphy \& Blumenthal, 2000; Winstok, 2006). More specifically, these researchers found that witnessing or experiencing verbally aggressive tactics used by parents in conflict was related to college women's use of verbal aggression in conflict with their boyfriends. Salari and Baldwin (2002) further found that levels of aggression used in intimate relationships tended to increase in severity over time.

In line with this finding, several researchers have reported that the use of verbal aggression in relationships often escalates into physical abuse (Katz, Carino, \& Hilton, 
2002; O’Leary, 1999; Salari \& Baldwin, 2002; Stets, 1990). Verbal aggression is the first stage of a continuum of aggressive relationship behaviors, which is followed by physical aggression, severe physical aggression, and possible partner/ spousal homicide (Murphy, 2000; Murphy \& O’Leary, 1989; Schumacher \& Leonard, 2005; Winstok, 2006). In a cross-sectional study, Sabourin, Infante, and Rudd (1993) found that distressed, violent couples evidenced greater reciprocity of verbal aggression than distressed nonviolent couples. Murphy \& Blumenthal (2000) similarly found that parent-child aggression in the family of origin significantly increases the likelihood of both the perpetration and victimization of violence in emerging adults' intimate relationships. In much of the theoretical and research literature addressing this issue, verbal aggression is viewed not only as a correlate but also as an antecedent or cause of physical violence in relationships.

Social Learning Theory

Studies examining the influence of family of origin on aggression outcomes have primarily used social learning theories to examine these phenomena. Social learning theory is an all-encompassing view of aggression, its triggers, and how individuals attain and maintain its use (Snethen \& Van Puymbroeck, 2008). Social learning theory posits that all individuals are born with the neurophysiological capacity to behave aggressively, but whether or not they do so is dependent on appropriate stimulation and level of cortical control (Bandura, 1973). According to Bandura, there are three regulatory systems that contribute to this process. The first of these are antecedent inducements, or stimuli that, through previous exposure and conditioning, set the stage for particular behaviors to occur. The second of these regulatory systems is response feedback, which involves the receipt of reinforcing or punishing consequences in response to particular 
behaviors, thereby influencing the likelihood that these behaviors will occur in the future. Finally, cognitive processes allow individuals to assess, interpret, and predict response feedback. While all individuals are capable of aggression, according to social learning theory aggressive behavior must be learned, triggered, and reinforced in order for it to be attained and maintained (Snethen \& Van Puymbroeck, 2008).

Early research using social learning theory focused on physical aggression specifically in children. Researchers found that children learn appropriate behavior through the observation of modeled behavior. Through witnessing or experiencing aggression in their families of origin, children learn that it serves a functional value for the aggressor (Bandura, 1973). Because children grow to respect and admire primary caregivers, they are more likely to observe and learn the behavior modeled by these individuals, thus adding it to their own repertoire for future use (Bandura, 1973). This theoretical assertion highlights the important role of primary caregivers in social learning theory.

Building upon this, researchers utilized social learning theory to examine familial violence (Bandura, 1973; Halford et al., 2000; Hines \& Saudino, 2002; Kalmuss, 1984; Skuja \& Halford, 2004; Wekerle \& Wolfe, 1999). These studies found that when one or both parents behave aggressively toward the other, children learn to view aggression as an appropriate response to conflict in intimate relationships and become more likely to use aggression in their own intimate relationships (Bandura, 1973; Halford et al., 2000; Hines \& Saudino, 2002; Kalmuss, 1984; Skuja \& Halford, 2004). According to Kalmuss (1984) there are two types of modeling involved in the intergenerational transmission of relationship aggression. First, generalized modeling occurs when parents communicate to 
children that aggression between family members is acceptable. The second type, specific modeling, occurs when individuals replicate the same types of aggression that they witnessed in their own families of origin. Findings from these studies contribute to our understandings of how exposure to parental conflict influences children's understandings of conflict resolution (Wekerle \& Wolfe, 1999). Unfortunately, however, in comparison to the literature on children, research on the long-term effects of interparental conflict on normative adult populations is sparse.

Identifying the significance of parental verbal aggression is particularly important for researchers examining Hispanic college populations as familism has been identified as a primary socialization institution (Sabogal, Marín, Otero-Sabogal, Marín \& PérezStable, 1987). A core characteristic in the Hispanic culture, familism is a cultural framework of family "connectiveness," meaning that parental messages- both direct and indirect- are expected to shape daughters beliefs about appropriate dating behaviors, intimacy, and interpersonal interactions (Hovell et al., 1994; Raffaelli \& Ontai, 2001; Raffaelli \& Suárez-al-Adam, 1998; Villaruel, 1998). Thus, the significant influence of parental processes on Hispanic college women's identity and dating development highlights the importance of exploring parent verbal aggression processes, and their relationship to daughters' intimate partner outcomes.

\section{Interparental Verbal Aggression}

Clearly, theoretical assertions and empirical research posit that there is a need to examine interparental displays of conflict to understand how Hispanic college women learn to negotiate conflicts- including the use of verbal aggression- in their own relationships. It is important to now identify how these parental conflict processes shape 
Hispanic daughters' use of appropriate relationship interactions, given parent-child relationship in Hispanic communities has been identified as a primary moderator of life experiences (Sabogal et al., 1987; Villaruel, 1998). For example, Cummings, GoekeMorey, and Papp (2003) found that children reportedly felt happy after seeing their parents' discuss issues calmly, show support for one another (listen, try to understand), and maintain affection (hold hands). In contrast, children's rate of destructive conflict tactics was related to parental reports of marital discord (Cummings, Goeke-Morey, \& Papp, 2003). Clearly, how parents interact with each other serves to communicate beliefs about love, acceptance, trust and intimacy, all of which may have implications for understanding how Hispanic college women learn skills to negotiate conflict in relationships outside the family of origin.

There is a large body of literature examining marital conflict, which is viewed as a normal and acceptable part of relationship patterns (Cummings, Goeke-Morey, \& Papp, 2003; Madden \& Janoff-Bulman, 1981). McGonagle, Kessler, and Gotlib (1992) found that in stable married couples the frequency of overt disagreements averaged once or twice a month. These same rates of disagreement tend to continue over time, meaning that conflict is a continuing aspect of martial relationships (Fincham \& Beach, 1999; McGonagle et al. 1992; Noller, Feeney, Bonnell, \& Callan, 1994). Conflict styles are the key to defining the degree to which marital conflict become severe, increasing, or harmful. An increase in marital conflict and the use of negative conflict resolution styles, such as a competitive or attacking style, have been linked to lower rates of marital satisfaction (Greeff \& De Bruyne, 2000) and increased depressive symptoms (Kouros \& Cummings, 2011) in wives. These depressive symptoms can in turn further negatively 
influence the way individuals resolve marital conflict, making them more likely to withdraw or lash out verbally or physically toward their spouse when in conflict (Marchand \& Hock, 2000).

The presence of children further increases the likelihood of conflict, so witnessing interparental conflict is also a natural part of child developmental experiences. However, it is the quality and quality of the conflict that distinguishes its influence on sons and daughters perceptions of conflicts, psychological well- being, and future conflict styles in intimate relationships. For example, studies examining white and African American populations have found that the conflict resolution style experienced/witnessed in the family of origin significantly predicts the conflict resolution style that college students use in their intimate relationships (Bandura, 1973; Van Doorn, Brangem \& Meeus, 2007; Halford et al., 2000; Hines \& Saudino, 2002; Kalmuss, 1984; Milletich, Kelley, Doane, \& Pearson, 2010; Skuja \& Halford, 2004; Wekerle \& Wolfe, 1999; White, 1999). For instance, Black, Sussman, \& Unger (2010) found that parents' use of verbal aggression significantly predicts college students' use of verbal aggression in their intimate relationships. More specifically, in a study on African American college students, Clark, Beckett, Wells, and Dungee-Anderson (1994) found that parental use of verbal aggression was predictive of females' use of verbal aggression against their intimate partners. Further, Martin (1990) found that verbal aggression between fathers and daughters predicted intimate relationship difficulties for daughters.

Unfortunately, no studies specifically consider verbal aggression in Hispanic marital relationships' influence on daughters' outcomes. Void in the research is concern that conceptions of appropriate verbal conflict differ among Hispanic couples. Korbin 
(1991) has noted that that every culture defines some behavioral acts that are abusive or deviant from acceptable standards; they vary in form and rate. Thus, is not always clear, however, whether what the research defines as verbal or emotional aggression is viewed as normal in one's own culture. For example, meta- analysis found a positive association between male domination in the family and/or verbal marital conflict and violence toward the woman in the couple. Given the assumption of machismo occurring in Hispanic families, it is possible that the usage of verbal aggression is fairly high in some marital relationships, and may become viewed as a normal form of marital conflict management.

\section{Parent- Daughter Verbal Aggression}

As the most proximal influence on their children, parents' interactions play a primary role in preparing daughters for intimate relationships. Sexual and intimate relationship socialization of children occurs through parental interactions which establish daughters' ideas about themselves self as a member of a couple or relationship dyad (O’Sullivan, Meyer-Bahlburg, \& Watkins, 2001; Raffaelli, \& Ontai, 2001; Stephens, Fernandez, \& Richman, in press).

Although much of the literature examining the influence of parents on Hispanic daughters' intimate relationships in emerging adulthood focuses on partner selection (e.g. Buunk \& Solano, 2010), sexuality expectations (e.g. O’Sullivan, Meyer-Bahlburg, \& Watkins, 2001; Raffaelli, \& Ontai, 2001), and physical aggression (e.g. Lehrer, Lehrer, \& Zhao, 2010), none specifically examine verbal aggression in intimate relationships. It is important to look at this specific form of conflict among parents to understand how these behaviors influence daughters' perpetration or acceptance of verbal aggression in their own intimate relationships. 
Knowledge about interparental verbal aggression can provides us information about parent- child conflict patterns. Several studies have found that the presence of marital violence in families is highly correlated with parent-child aggression (Blumenthal, Neemann, \& Murphy, 1998; Hughes, 1988; Jouriles, Murphy, \& O’Leary, 1989). Using a meditational model, Cui et al. (2010) similarly found the relationship between exposure to interparental violence and subsequent perpetration and victimization in intimate relationships to be mediated by the level of aggression demonstrated by the parent toward the participant.

Parents' direct and indirect communications of acceptance, affection, and positive regard, as expressed through both the parent- parent and parent-child relationship interactions, have been positively associated with daughters' intimate relationship outcomes (Andrews, Foster, Capaldi, \& Hops, 2000; Crockett \& Randall, 2006), reinforcing the importance of examining how parents' problem solving and inductive reasoning techniques influence Hispanic women's views of verbal aggression in dating relationships. For example, conflict in the parent-adolescent relationship conflicts has been found to be associated with subsequent aversive communication in various outcomes in emerging adult's intimate relationships (Andrews et al., 2000; Linder \& Collins, 2005). Andrews et al. (2000) found that aversive communication in the family of origin during adolescence was associated with less satisfaction, more aversive communication, and more physical aggression in these subsequent intimate relationships. Similarly, Crockett and Randall (2006) found that individuals who reported positive family relationships as adolescents were more likely to use discussion, a more rational 
method of conflict resolution, in their intimate relationships as emerging adults, and to therefore feel more satisfied in these relationships.

Hispanic college women and parents experience unique conflictual issues regarding intimate relationship expectations, dating/ intimacy values and expectations (Dennis, Basañez, \& Farahmand, 2010; Stephens, Fernandez \& Richman, in press). Even among highly acculturated Hispanic families, parental traditional cultural values have been found to be a source of conflict between parents and their college age daughters, particularly as it related to gendered behavioral expectations in intimate relationships (Falicov, 1998; Hovell et al, 1994; O’Sullivan, Meyer-Bahlburg \& Watkins, 2001; Stephens, Fernandez, \& Richman, in press). 


\section{METHODS}

\section{Participants}

A convenience sample of 599 female Hispanic college students participated in this study. Students aged 18 to 21 were recruited through the Department of Psychology Research pool known as Sona Systems and participants earned extra course credit for their participation in this study. Participants mean age was 19.03 years. All participants were of Hispanic origin, with 230 (37.7\%) self-identifying as Cuban, 117 (19.2\%) selfidentifying as American, 60 (9.8\%) self-identifying as Colombian, 41 (6.7\%) selfidentifying as Puerto Rican, 31 (5.1\%) self-identifying as Venezuelan, and the remaining $131(21.5 \%)$ self-identifying as being from various South American and Caribbean countries (see Table 1). The majority of participants were freshman (50.9\%), followed by juniors $(25.5 \%)$, sophomores $(14.5 \%)$, and seniors (9\%). Most were living at home with both parents $(\mathrm{N}=324)$ or with just their mother $(\mathrm{N}=127)$ (see Table 2). When considering their dating status at the time of data collection, 395 reported they were dating one person $(65.9 \%)$ were dating one person, while 183 were not in a relationship (30.6\%) (see Appendix D, Table 3).

\section{Measures}

Demographic Questionnaire

Participants were asked to report demographic information regarding age, nationality, their own relationship status, living situation, and year in school.

Age. Participants were asked to report the month and year of their birth in order to calculate their age. 
Nationality. In addition to ethnicity, participants were also asked to report their nationality. This was an open-ended question so as not to limit participants' answers.

Participants' relationship status. Participants were asked to report their relationship status in terms of whether they are "Not dating anyone," "Dating one person," "Dating two people," or "Dating several people."

Year in school. Participants were presented with a drop-down menu and asked to report their year in school based on the number of credits they have obtained. Options presented were "Freshman", "Sophomore", "Junior", and "Senior."

Current living situation. Participants' current living situation will be assessed by asking whether they presently reside with: "Two parents," "Just my mother," "Just my father," "foster parent(s)," "Aunt or Uncle," "Grandparents," or "Other." Conflict Tactics Scale (CTS)

The Conflict Tactics Scale (CTS) measures styles of conflict resolution between family members. As we were only interested in parental and child verbal aggression responses, the current study only utilized the Conflict with Parents and Mother-Father Conflict Resolution verbal aggression items (see Appendix A). The verbal aggression portion of the CTS asks respondents questions such as how many times each person involved in the conflict "Yelled and/or insulted (the other person)," "Sulked and/or refused to talk about it," and "Threatened to hit or throw something at the other (person)." The CTS has been shown to have good validity in the factor structure of all aggression subscales (Straus \& Gelles, 1990, as cited in Fischer \& Corcoran, 2007). For the present study, sixteen alpha coefficients ranging from .62 to .88 are available for the verbal aggression subscale. Furthermore, evidence exists to support the concurrent 
validity of the CTS in the agreement between family members about the conflict tactics used (Straus \& Gelles, 1990, as cited in Fischer \& Corcoran, 2007). Individual forms have not been evaluated for reliability or validity.

Conflict with Parents Form. The Conflict with Parents form assesses how adolescents and parents handle conflict with each other (Fischer \& Corcoran, 2007). Participants are asked to report the number of times they and their parents have participated in certain actions in response to conflict with each other over the previous year on a scale of 0 (Never) to 5 (More than once a month).

Mother-Father Conflict Resolution Form. The Conflict with Parents form includes questions about how parents handle conflict with each other (Fischer \& Corcoran, 2007). Participants are asked to report the number of times their parents have participated in certain actions in response to conflict with each other over the previous year on a scale of 0 (Never) to 5 (More than once a month).

Conflict in Adolescent Dating Relationships Inventory (CADRI)

The CADRI is used to assess abusive behavior in adolescent dating relationships (Fischer \& Corcoran, 2007). Participants are asked to rate how often certain actions have been taken by themselves and their partners while in conflict over the course of the relationship on a scale of 1-4 $(1=$ Never, $4=$ Often $)$. The current study utilized only the Verbal or Emotional Abuse (VE) subscale (see Appendix B). These items ask respondents questions such as how many times, when in conflict with their significant others in the past year, they have "brought up something bad that he had done in the past," "insulted him with put downs," and "threatened to end the relationship." The CADRI has been found to have a fair internal consistency with an alpha in the mid-.80s 
for the Verbal Abuse subscale (Wolfe et al., 2001, as cited in Fischer \& Corcoran, 2007). The CADRI also has good test-retest reliabilities, ranging from .28 for Sexual Abuse to the mid $-.50 \mathrm{~s}$ and $.60 \mathrm{~s}$ for the remaining six scales.

Procedure

Approval for the current study was obtained from the Institutional Review Board at Florida International University. The study was then posted on Sona Systems and appeared to students on a list of studies recruiting participants at that time. The listing gave a description of the study and upon reading the study details, students had the option to participate or not to participate.

Prior to beginning the survey, students were shown a screen containing a Consent Form and asked to click a link acknowledging their consent to participate in the study. Students had the option to either give consent or leave the study and return to the list of available studies. Once consent was obtained, students were allowed to complete the online survey anonymously. Upon completion of the survey, students were directed to an entirely separate survey where they were asked to enter their name, student ID number, and date of birth in order to receive credit for their participation. The survey containing questions about participants' identifying information was in no way linked to the survey used in this study to allow for complete anonymity. 


\section{DATA ANALYSIS}

Structural Equation Modeling (SEM) was pursued with AMOS version 17.0 because it is an analytic technique that allows for the investigation of direct and indirect relationships between one or more independent variables and one or more dependent variables. The SEM methodology is designed to accommodate models that include latent variables, reciprocal causation, measurement error, interdependence and simultaneity. It is useful for examining multidimensional relationships and is the only analysis that provides complete and concurrent tests of all the relationships. Overall, SEM is a more powerful statistical technique than multiple regression or path analysis, with more flexible assumptions. Unlike more traditional statistical approaches, SEM also considers measurement error (Hoyle \& Panter, 1995; Kline, 1998).

Using structural equation modeling (SEM) for these reasons and because of its ability to separate common and unique components of variance, which minimizes the effects of any unreliability due to measurement error, this study tested the model depicted in Figure 1 (Appendix F). 


\section{RESULTS}

\section{Preliminary analyses}

Table 4 in Appendix E presents the means and standard deviations for all of the continuous variables used in the model. The median values for each of the variables (not reported) were close to the mean values. A total of $87 \%$ of participants reported witnessing at least one instance of verbal aggression by their mothers toward their fathers, and $85.6 \%$ reporting having witnessed at least one instance of verbal aggression by their fathers toward their mothers in the past year. A total of $87.1 \%$ and $76 \%$ of participants reported experiencing verbal aggression from their mothers and fathers, respectively, at least once in the past year. The majority (97\%) of participants reported having used verbal aggression toward their significant others at least once in the past year.

Univariate indices of skewness and kurtosis were examined to determine if the absolute value of any of these indices was greater than 2.0. On the basis of this criteria, skewness and kurtosis (see Appendix E, Table 5) were within acceptable ranges. Outliers were evaluated prior to analysis by calculating a mean leverage score for each participant based on their multivariate profile for the six variables included in the model analysis. The mean leverage score across respondents was .007 and an outlier was defined as anyone having a leverage score four times the value of the mean. A small number of outliers were found and discarded $(\mathrm{N}=11)$. The model contained no missing data.

$$
\text { Primary Analyses }
$$

On the basis of the recommendations of Bollen and Long (1993), acceptable model fit indices were pre-specified. Specifically, indices of absolute fit, indices of 
relative fit and parsimony-adjusted fit indices were used to test model fit. The overall chi square test of model fit was examined and statistically non-significant chi square values (indicated by a Bollen-Stine corrected $p$ value greater than .05) indicated good model fit. The Comparative Fit Index (CFI) was examined and values of .95 or greater was used to define good model fit. The Goodness of Fit Index (GFI) was examined and values of .90 or greater indicated a good model fit. The Root Mean Square Error of Approximation (RMSEA) was examined; values less than 0.05 indicated a good model fit. The $p$ value for Close fit test was examined and values that were statistically non-significant (greater than .05) indicated a good model fit. Finally, the Standardized Root Mean Square Residual (SRMR) was examined and values less than .05 indicated a good model fit. In addition to the global fit indices, more focused tests of fit were examined. Modification indices of notable size (values of 4.0 or greater) were evaluated to see if there were any conceptual rationales for modifying the model. Additionally, standardized residual values were evaluated. Any values falling outside of the range of -2.0 and 2.0 were considered points of stress in the model and sources of ill fit.

Figure 1 (Appendix F) visually represents the model used for the current study. All fit indices evaluated were consistent with good model fit. The overall chi square test of model fit was statistically non-significant, $\chi^{2}(3)=3.088, p=.378$. The Comparative Fit Index (CFI) was 1.000. The Goodness of Fit Index (GFI) was .998. The Root Mean Square Error Approximation (RMSEA) was .007 and the p-value associated with the RMSEA was .817. The Standardized Root Mean Square Residual (SRMR) was .0161. Figure 1 presents both unstandardized and standardized path coefficients, with unstandardized coefficients in parentheses. 


\section{Mother-Daughter Verbal Aggression}

As hypothesized, Figure 1 shows a significant path coefficient between mother's use of verbal aggression toward the father and the mother's use of verbal aggression toward the daughter. More specifically, as mothers' use of verbal aggression toward the father increases by one standard deviation, mother's use of verbal aggression toward the daughter increases by .53 standard deviations. Equivalently, as mothers' use of verbal aggression toward the father increases by one unit, mothers' use of verbal aggression toward the daughter increases by .50 units. Further, a significant path coefficient is also shown between mother's use of verbal aggression toward the daughter, and the daughter's use of verbal aggression toward her significant other. Specifically, as mothers' use of verbal aggression toward the daughter increases by one standard deviation, the daughters' use of verbal aggression toward her significant other increases by .20 standard deviations. Equivalently, as mothers' use of verbal aggression toward the daughter increases by one unit, the daughters' use of verbal aggression toward her significant other increases by .35 units.

\section{Father-Daughter Verbal Aggression}

Figure 1 also shows a significant path coefficient between father's use of verbal aggression toward the mother and the father's use of verbal aggression toward the daughter. More specifically, as fathers' use of verbal aggression toward the mother increases by one standard deviation, fathers' use of verbal aggression toward the daughter also increases by .51 standard deviations. Equivalently, as fathers' use of verbal aggression toward the mother increases by one unit, fathers' use of verbal aggression toward the daughter also increases by .43 units. However, the path between fathers' use 
of verbal aggression toward the daughter and the daughter's use of verbal aggression toward her significant other was statistically non-significant. 


\section{DISCUSSION}

The purpose of the current study was to evaluate the relation between parental use of verbal aggression and Hispanic college women's use of verbal aggression in romantic relationships. It was expected that parents' use of verbal aggression with each other would predict their use of verbal aggression with their daughters. Further, it was predicted that these interactions would predict daughters' use of verbal aggression in their romantic relationships. These hypotheses were partially supported; each relationship is discussed below.

\section{Interparental Verbal Aggression}

Results showed that mothers' and fathers' use of verbal aggression toward each other predicted their use of verbal aggression toward their daughters. These findings are consistent with similar past research which has shown that marital abuse and child abuse tend to be reciprocal events (Hamel, 2005; Rumm, Cummings, Krauss, Bell, \& Rivara, 2000). For instance, Rumm et al. (2000) found that families who had reported at least one incidence of spousal abuse were twice as likely to have reported at least one confirmed case of child abuse. While these parents may simply be more inclined to use verbal aggression in general, this finding may suggest that children could be the victims of their parents' displaced aggression toward each other. Future research should further investigate this link.

The relationship found between mothers' use of verbal aggression toward fathers and fathers' use of verbal aggression toward mothers is likely the result of the reciprocal and cyclical in nature of verbal aggression (Atkin, Smith, Roberto, Fediuk, \& Wagner, 2002; Infante, Sabourin, Rudd, \& Shannon, 1990; Rancer \& Avtgis, 2006). In accordance 
with the findings of the current study, Infante et al. (1990) found that verbal aggression tended to be used reciprocally among husbands and wives. Couples may use verbal aggression reciprocally because a verbally aggressive attack by one person prompts an equally aggressive response, creating a cycle of verbally aggressive behavior which eventually develops into a long-term pattern (Atkin, et al., 2002; Infante, et al., 1990).

Mothers' use of verbal aggression toward fathers was found to be negatively correlated with external factors related to fathers' use of verbal aggression toward daughters. In other words, the less verbal aggression mothers used toward fathers, the more external factors contributed to fathers' use of verbal aggression toward daughters. Other factors noted in the literature that may contribute to fathers' use of verbal aggression toward their daughters include a history of child abuse and anger management problems (Jackson et al., 1999). In this case, when there is no verbal aggression between parents, external factors in fathers' lives appear to be contributing a great deal to their use of verbal aggression with their daughters. So, the less verbal aggression is occurring between parents, the more external factors, as opposed to inter-parental aggression, contribute to fathers' use of verbal aggression toward daughters.

\section{Mother- Daughter Verbal Aggression}

The error scores associated with mothers' verbal aggression toward daughters and fathers' verbal aggression toward daughters were also positively correlated, suggesting that the more external factors contributed to one, the more they contributed to the other. As mentioned previously, Jackson et al. (1999) found that parents who use verbal aggression toward their children tended to have problems with anger management and a history of childhood abuse, which may contribute to parents' use of verbal aggression not 
explained by the model. Further, the same study found that the older children were the more likely parents were to use verbal aggression toward them, which may at least partially explain the prevalence of reported verbal aggression in the current study. Interestingly, this study also found that parents who used verbal aggression toward their children also tended to physically abuse their children. One explanation for why parents who have used verbal aggression with their children tended to also abuse them physically may be because verbal abuse tends to precede physical abuse in many cases (Katz, Carino, \& Hilton, 2002; O’Leary, 1999; Stets, 1990). Future research should investigate the link between verbal and physical abuse in families.

The current study's finding that mothers' verbal aggression toward their daughters predicted daughters' use of verbal aggression toward their significant others is consistent with previous research which shows that mothers' use verbal aggression predicts the use of verbal aggression in their adult daughters (Roberto, McClure, \& McFarland, 2003; Webber \& Patterson, 1997). As mentioned previously, Kalmuss (1984) asserts that specific modeling is an integral part of the intergenerational transmission of relationship aggression. So, when mothers use verbal aggression, it appears that they demonstrate that it is an acceptable and normal way to handle conflict in relationships, thereby making it more likely that their daughters will also use it in their own romantic relationships.

Father- Daughter Verbal Aggression

The current study's finding that fathers' verbal aggression toward daughters did not predict daughters' use of verbal aggression toward their significant others is also consistent with previous research which found that fathers have been found to play a less significant role in the development of their children's acquisition and use of verbally 
aggressive behavior than mothers do (Roberto, McClure, \& McFarlane, 2003). Past research has shown that many daughters do not feel as close with their fathers as they do with their mothers (Nielsen, 2004; Youniss \& Ketterlinus, 1987). According to Nielsen (2004), college women reported their relationships with their mothers to be significantly more communicative, comfortable, and emotionally intimate than their relationships with their mothers. The fact that many daughters have reported having less intimate relationships with their fathers than their mothers may explain why fathers' communication with them does not appear to influence their behavior in intimate relationships the way their mothers' communication does. These results should be read with caution and not be misinterpreted to mean that fathers' behavior is not important. The results of this study show that fathers' verbally aggressive behavior is correlated with mothers' verbally aggressive behavior, which was found to predict daughters' use of verbal aggression. Therefore, although fathers' use of verbally aggressive behavior toward daughters was not found to directly predict daughters' use of verbal aggression in their romantic relationships, the results of this study suggest that there may be an indirect link between these two variables. Prior research suggests that several factors, including anger management problems, history of abuse, and beliefs about verbal aggression, may make fathers more apt to use aggression toward daughters (Jackson, et al., 1999), as well as toward their partners (Baker \& Stith, 2008). Future studies could investigate these factors to assess whether they may mediate the relationship between fathers' use of verbal aggression in the family of origin and daughter's use of verbal aggression in their intimate relationships. 
Overall, the results of this study are consistent with social learning theory, which posits that children learn appropriate relationship behaviors from their same-sex parents (Grusec \& Brinker, 1972; Jankowski, Leitenberg, Henning, \& Coffey, 1999; Perry \& Bussey, 1979). Daughters' verbal aggression toward their significant others was predicted by mothers', but not fathers', use of verbal aggression, suggesting that, while both mothers and fathers can serve as role models for their children, it is particularly important for mothers to be aware of the way they speak around their daughters and to their daughters, as they are more likely to replicate their mothers' verbally aggressive behavior than their fathers'.

\section{Limitations}

The majority of participants in the present study reported that they were residing with one or both parents. Residing with parents may not be typical of many young adults, particularly those attending college. Similarly, the study did not control for living situation, which may influence results, particularly if the participant lives with parents or significant other. Future studies should control for participants' housing arrangements, taking special consideration to whether they live with parents or their significant others.

Although the use of an online survey has several benefits, including the potential for a larger sample size through access to a particular population that would likely otherwise not be as readily available, as well the ability for participants to respond to surveys completely anonymously, it also limits the ability of respondents to ask questions that may arise while completing the survey, potentially limiting some accuracy in the data, particularly when reporting certain demographic information. Future studies should 
replicate this study using a paper survey to assess whether there are differences in the findings.

Finally, because the current study only included females, it is unclear how their male partners' experiences with intergenerational verbal aggression would affect females use or acceptance of verbal aggression. Because verbal aggression tends to be reciprocal in nature (Rancer \& Avtgis, 2006), dating a partner who was exposed to this type of aggression in his family of origin may influence women's experiences in their intimate relationships, even if they were not exposed to verbal aggression in their own family of origin. Future research should examine the role of exposure to verbal aggression in the family of origin and how this affects beliefs about appropriate relationship behaviors in college-aged males. Further, future research should investigate whether both partners having been exposed to verbal aggression in their families of origin influences the frequency and severity of these behaviors in intimate relationships.

\section{Conclusion}

While I recognize these limitations, the findings represent an important step toward adding to what is currently a small body of research about Hispanic college women's use of verbal aggression within intimate relationships. The current study contributes to the literature by examining the intergenerational pattern of verbal aggression in the Hispanic female college population, providing evidence that use of verbal aggression both in the families and intimate relationships in the current sample is alarmingly common. The results of this study were consistent with past research indicating that mothers play a more significant and direct role than fathers do in teaching 
daughters appropriate relationship behaviors. The study reported in this paper provides evidence that Hispanic daughters learn to use verbal aggression in their intimate relationships from their parents' use of verbal aggression. More specifically, daughters directly learn to use verbal aggression from their mothers. Although a direct link was not found between fathers' use of verbal aggression toward daughters and daughters' use of verbal aggression in their intimate relationships, an indirect link appears to be present between these variables as well.

The current study's findings provide evidence in support of undertaking early intervention efforts in order to end the cycle of abuse. Interventions efforts should focus on confronting parents' beliefs about verbal aggression being an acceptable way to resolve conflict. Because verbal aggression is not always acknowledged as abuse, parents and children should be educated regarding what constitutes abuse, how verbal aggression can escalate into more severe types of abuse, and taught healthier techniques for conflict resolution. There are several evidence-based programs could be used to intervene with parents who have been involved in intimate partner violence and their children who have witnessed it such as the Get Real About Violence program (Meyer, Roberto, Boster, \& Roberto, 2004) for students in grades k-12; the Second Step Violence Prevention Program, which includes a family component to inform the students' families about the curriculum so that they can reinforce what the children learn at home; and The Adults and Children Together (ACT) Against Violence program, which targets parents of children from 0-8 years who have been victims of partner violence. Carr and VanDeusen (2002) assert that the college campus is an ideal location to implement IPV/conflict resolution intervention and prevention programs because of the high prevalence rates of 
IPV reported among college students. Although few evidence based programs exist at the college level, research suggests that in order to increase effectiveness, these programs should include peer education, target attitudes toward dating violence, and be relatable to participants' life contexts (Schwartz, Griffin, Russell, \& Frontaura-Duck).

Though exploratory, this study's findings provide new insights into the importance of identifying Hispanic women's conflict tactics within their intimate relationships. It is evident it is particularly important that this research focus on college students and young adults who may be forming the beliefs about verbal aggression as an appropriate method of conflict resolution. As rates of intimate partner violence continue to rise, particularly within Hispanic populations, there is a need for further research examining factors influencing attitudes and behavioral outcomes occurring among Hispanic college populations. 


\section{REFERENCES}

Andrews, J. A., Foster, S. L., Capaldi, D., \& Hope, H. (2000). Adolescent and family predictors of physical aggression, communication, and satisfaction in young adult couples: A prospective analysis. Journal of Consulting and Clinical Psychology, 68, 195-208.

Atkin, C., Smith, S., Roberto, A., Fediuk, T., \& Wagner, T. (2002). Correlates of verbally aggressive communication in adolescents. Journal of Applied Communication Research, 30(3), 251-268.

Baker, C. \& Stith, S. M. (2008). Factors predicting dating violence perpetration among male and female college students, Journal of Aggression, Maltreatment, \& Trauma, 17(2), 227-244.

Bandura, A. (1973). Aggression: A social learning analysis. Englewood Cliffs, NJ: Prentice-Hall.

Black, D. S., Sussman, S., Unger, J. B. (2010). A further look at the intergenerational transmission of violence: Witnessing interparental violence in emerging adulthood. Journal of Interpersonal Violence, 25, 1022-1042.

Blumenthal, D. R., Neemann, J., \& Murphy, C. M. (1998) Lifetime exposure to interparental physical and verbal aggression and symptom expression in college students. Violence and Victims, 13(2), 175-196.

Bollen, K. A., \& Long, J. S. (1993). Testing structural equation models. Newbury Park, CA: Sage.

Buunk, A. P. \& Solano, A. C. (2010). Conflicting preferences of parents and offspring over criteria for a mate: A study in Argentina. Journal of Family Psychology, 24, 391-399.

Carr, J. L. \& VanDeusen, K. M. (2002). The relationship between family of origin violence and dating violence in college men. Journal of Interpersonal Violence, $17,630-646$.

Clark, M. L., Beckett, J., Wells, M., \& Dungee-Anderson, D. (1994). Courtship violence among African American college students. Journal of Black Psychology, 20, 264281 .

Coker, A, L., Smith, P. H., Bethea, L., King, M. R., McKeown, R. E. (2000). Physical health consequences of physical and psychological intimate partner violence. Archives of Family Medicine, 9, 451-457. 
Coker, A. L. et al. (2002). Physical and mental health effects of intimate partner violence for men and women. American Journal of Preventative Medicine, 23, 260-268.

Crockett, L. J. \& Randall, B. A. (2006). Linking adolescent family and peer relationships to the quality of young adult romantic relationships: The mediating role of conflict tactics. Journal of Social and Personal Relationships, 23, 761-780.

Cui, M., Durtschi, J. A., Donnellan, M. B., Lorenz, F. O., \& Conger, R. D. (2010). Intergenerational transmission of relationship aggression: A prospective longitudinal study. Journal of Family Psychology, 24, 688-697.

Cummings, E. M., Goeke-Morey, M. C., \& Papp, L. M. (2003). Children's responses to everyday marital conflict tactics in the home. Child Development, 74, 1918-1929.

Dennis, J., Basañez, T. \& Farahmand, A. (2010). Intergenerational conflicts among Latinos in early adulthood: Separating values conflicts with parents from acculturation conflicts. Hispanic Journal of Behavioral Sciences, 32, 118-135.

Dowd, L. S., Leisring, P. A., \& Rosenbaum, A. (2005). Partner aggressive women: Characteristics and treatment attrition. Violence and Victims, 20(2), 219-33.

Edelson, M. G., Hokoda, A., \& Ramos- Lira, L. (2007). Differences in effects of domestic violence between Latina and non-Latina women. Journal of Family Violence, 22, 1-10.

Esteban, E. J. (2006). Parental verbal abuse: Culture-specific coping behavior of college students in the Philippines. Child Psychiatry and Human Development, 36, 243259.

Falicov, C. J. (1998). Latino families in therapy. New York: Guilford Press.

Fincham, F. D. \& Beach, S. R. H. (1999). Conflict in marriage: Implications for working with couples. Annual Review of Psychology, 50, 47-77.

Fischer, J. \& Corcoran, K. (2007). Measures for clinical practice and research: A sourcebook volume 1: Couples, families, and children. Fourth Edition. USA: Gower Publishing Company, Limited.

Greeff A. P. \& De Bruyne, T. (2000). Conflict management style and marital satisfaction. Journal of Sex \& Marital Therapy, 26, 321-334.

Grusec, J. E. \& Brinker, D. B. (1972). Reinforcement for imitation as a social learning determinant with implications for sex-role development. Journal of Personality and Social Psychology, 21, 149-158. 
Halford, W. K., Sanders, M. R., \& Behrens, B. C. (2000). Repeating the errors of our parents? Family-of-origin violence and observed conflict management in engaged couples. Family Process, 39, 219-235.

Hamel, J. (2005). Gender-inclusive treatment of intimate partner abuse: A comprehensive approach. New York: Springer.

Harned, M. S. (2001). Abused women or abused men? An examination of the context and outcomes of dating violence. Violence and Victims, 16(3), 269-285.

Hegarty, K., Gunn, J., Chondros, P., \& Small, R. (2004). Association between depression and abuse by partners of women attending general practice: Descriptive, cross sectional survey. $B M J, 328,621-624$.

Hines, D. A. (2007). Predictors of sexual coercion against women and men: A multilevel, multinational study of university students. Archives of Sexual Behavior, 36, 403422.

Hines, D. A., \& Saudino, K. J. (2002). Intergenerational transmission of intimate partner violence: A behavioral genetic perspective. Trauma, Violence, \& Abuse, 3, 210225 .

Hovell, M., Sipan, C., Blumberg, El., Atkins, C., Hofsteter, R., \& Kreitner, S. (1994). Family influences on Latino and Anglo adolescents' sexual behavior. Journal of Marriage and the Family, 56, 973-986.

Hoyle, R. H., \& Panter, A. T. (1995). Writing about structural equation models. In R. H. Hoyle (Ed.), Structural equation modeling: Concepts, issues, and applications (pp. 158-176). Thousand Oaks, CA: Sage Publications.

Hughes, H. M. (1988). Psychological and behavioral correlates of family violence in child witnesses and victims. American Orthopsychiatric Association, 58, 7-90.

Infante, D. A. (1995). Teaching students to understand and control verbal aggression. Communication Education, 44, 51-63.

Infante, D. A., Sabourin, T. C., Rudd, J. E., \& Shannon, E. A. (1990). Verbal aggression in violent and nonviolent marital disputes. Communication Quarterly, 38, 361371.

Infante, D. A, Trebing, J. D, Shepherd, P. A, \& Seeds, D. E. (1984). The relationship of argumentativeness to verbal aggression. The Southern Speech Communication Journal, 50, 67-77. 
Infante, D. A. \& Wigley, C. J. (1986). Verbal aggressiveness: An interpersonal model and measure. Communication Monographs, 53, 61-69.

Jackson, S. M. (1999). Issues in the dating violence research: A review of the literature. Aggression and Violent Behavior, 4, 233-247.

Jankowski, M. K., Leitenberg, H., Henning, K., \& Coffey, P. (1999). Intergenerational transmission of dating aggression as a function of witnessing only same sex parents vs. opposite sex parents vs. both parents as perpetrators of domestic violence. Journal of Family Violence, 14, 267-279.

Jezl, D. R., Molidor, C. E., \& Wright, T. L. (1996). Physical, sexual and psychological abuse in high school dating relationships: Prevalence rates and self-esteem issues. Child and Adolescent Social Work Journal, 13(1), 69-87

Jouriles, E. N., Murphy, C. M., \& O'Leary, K. D. (1989). Interspousal aggression, marital discord, and child problems. Journal of Consulting and Clinical Psychology, 57, 453-455.

Kalmuss, D. (1984). The intergenerational transmission of marital aggression. Journal of Marriage and Family, 46, 11-19.

Katz, J., Carino, A., \& Hilton, A. (2002). Perceived verbal conflict behaviors associated with physical aggression and sexual coercion in dating relationships: A gendersensitive analysis. Violence and Victims, 17, 93-109.

Katz, J., Moore, J. A., \& Tkachuk, S. (2007) Verbal sexual coercion and perceived victim responsibility: Mediating effects of perceived control. Sex Roles, 57(3-4), 235247. doi:10.1007/s11199-007-9253-X

Katz, J., Washington Kuffel, S., \& Brown, F. A. (2006). Leaving a sexually coercive dating partner: A prospective application of the investment model. Psychology of Women Quarterly, 30(3), 267-275. doi:10.1111/j.1471-6402.2006.00295.x

Kline, R. B. (1998). Principles and Practice of Structural Equation Modeling. New York: The Guilford Press.

Korbin, J. E. (1991). Cross-cultural perspectives and research directions for the $21 \mathrm{st}$ century. Child Abuse \& Neglect, 15, 67-77.

Kouros, C. D. \& Cummings, E. M. (2011). Transactional relations between marital functioning and depressive symptoms. American Journal of Orthopsychiatry, 81, 128-138. 
Lehrer, J. A., Lehrer, E. L., \& Zhao, Z. (2010). Physical dating violence victimization in college women in Chile. Journal of Women's Health, 19, 893-902.

Linder, J. R. \& Collins, W. A. (2005). Parent and peer predictors of physical aggression and conflict management in romantic relationships in early adulthood. Journal of Family Psychology, 19, 252-262.

Luthra, R. \& Gidycz, C. A. (2006). Dating violence among college men and women: Evaluation of a theoretical model. Journal of Interpersonal Violence, 21, 717-731.

Madden, M. E. \& Janoff-Bulman, R. (1981). Blame, control, and marital satisfaction: Wives' attributions for conflict in marriage. Journal of Marriage and the Family, 43, 663-674.

Marchand, J. F. \& Hock, E. (2000). Avoidance and attacking conflict-resolution strategies among married couples: Relations to depressive symptoms and marital satisfaction. Family Relations, 49, 201-206.

Martin, B. (1990). The transmission of relationship difficulties from one generation to the next. Journal of Youth and Adolescence, 19, 181-199.

McGonagle, K. A., Kessler, R. C., \& Gotlib, I. H. (1992). The effects of marital disagreement style, frequency, and outcome on marital disruption. Journal of Social and Personal Relationships, 10, 385-404.

Meyer, G., Roberto, A. J., Boster, F. J., Roberto, H. L. (2004). Assessing the Get Real about Violence ${ }^{\circledR}$ curriculum: Process and outcome evaluation results and implications. Health Communication, 16, 451-474.

Milletich, R. J., Kelley, M. L., Doane, A. N., \& Pearson, M. R. (2010). Exposure to interparental violence and childhood physical and emotional abuse as related to physical aggression in undergraduate dating relationships. Journal of Family Violence, 25, 627-637.

Muñoz-Rivas, M. J., Graña, J. L., O'Leary, K. D., \& González Lozano, M. P. (2007). Aggression in adolescent dating relationships: Prevalence, justification, and health consequences. Journal of Adolescent Health, 40, 298-304.

Muñoz-Rivas, M. J., Graña, J. L., O'Leary, K. D., \& González, M. P. (2009). Prevalence and predictors of sexual aggression in dating relationships of adolescents and young adults. Psicothema, 21(2), 234-240.

Murphy, C. M. \& Blumenthal, D. R. (2000). The mediating influence of interpersonal problems on the intergenerational transmission of relationship aggression.

Personal Relationships, 7, 203-218.00 
Murphy, C. M., \& O’Leary, K. D. (1989). Psychological aggression predicts physical aggression in early marriage. Journal of Consulting and Clinical Psychology, 57, $579-582$.

Nielsen, L. (2004). Embracing your father: How to build the relationship you've always wanted with your dad. NY: McGraw Hill.

Noller, P., Feeney, J. A., Bonnell, D., \& Callan, V. J. (1994). A longitudinal study of conflict in early marriage. Journal of Social and Personal Relationships, 11, 233252.

O’Hagan, K. P. (1995). Emotional and psychological abuse: Problems of definition. Child Abuse and Neglect, 19, 449-461.

O'Leary, K. D. (1999). Psychological abuse: A variable deserving critical attention in domestic violence. Violence and Victims, 14, 3-23.

O'Sullivan, L. F., Meyer-Bahlburg, H., \& Watkins, B. (2001). Mother-Daughter communication about sex among urban African American and Latino families. Journal of Adolescent Research, 16, 269-292.

Palazzolo, K. E., Roberto, A. J., \& Babin, E. A. (2010). The relationship between parents' verbal aggression and young adult children's intimate partner violence victimization and perpetration. Health Communication, 25, 357-364.

Perry, D. G. \& Bussey, K. (1979). The social learning theory of sex differences: Imitation is alive and well. Journal of personality and social psychology, 37, 1699-1712.

Pico-Alfonso, M. A. et al. (2006). The impact of physical, psychological, and sexual intimate male partner violence on women's mental health: Depressive symptoms, posttraumatic stress disorder, state anxiety, and suicide. Journal of Women's Health, 15, 599-611.

Raffaelli, M., \& Ontai, L. L. (2001). "She's sixteen years old and there's boys calling over to the house": An exploratory study of sexual socialization in Latino families. Culture, Health, and Sexuality, 3, 295-310.

Raffaelli, M. \& Ontai, L. L. (2004). Gender socialization in Latino/a families: Results from two retrospective studies. Sex Roles: A Journal of Research, 50, 287-299.

Raffaelli, M., \& Suarez-al-Adam, M. (1998). Reconsidering the HIV prevention needs of Latino women in the United States. In N. L. Roth and L.K. Fullers (Eds.), Women and AIDS: Negotiating safer practices, care, and representation (pp. 7-41). New York: Haworth. 
Rancer, A. S., \& Avtgis, T. A. (2006). Argumentative and Aggressive Communication: Theory, Research, and Application. Thousand Oaks: CA. Sage Publications.

Riggs, D. S., \& O'Leary, K. D. (1996). Aggression between heterosexual dating partners: An examination of a causal model of courtship aggression. Journal of Interpersonal Violence, 11, 519-540.

Roberto, A. J., McClure, L., \& McFarland, M. (2003, November). The relationship between parent verbal aggression and child verbal aggression and self-esteem. Paper presented to the Family Communication Division of the National Communication Association, Miami, FL.

Rumm, P. D., Cummings, P., Krauss, M. R., Bell, M. A., \& Rivara, F. P. (2000). Identified spouse abuse as a risk factor for child abuse. Child Abuse \& Neglect, 24(11), 1375-1381.

Sabogal, F., Marín, G., Otero-Sabogal, R., Marín, B., \& Pérez-Stable, E. J. (1987). Hispanic familism and acculturation: What changes and what doesn't? Hispanic Journal of Behavioral Sciences, 9, 397-412.

Sabourin, T. C., Infante, D. A., \& Rudd, J. E. (1993). Verbal aggression in marriages: A comparison of violent, distressed but nonviolent, and nondistressed couples. Human Communication Research, 20, 245-267.

Salari, S. M. \& Baldwin, B. M. (2002). Verbal, physical, and injurious aggression among intimate couples over time. Journal of Family Issues, 23, 523-550.

Schumacher, J. A. \& Leonard, K. E. (2005). Husbands' and wives' marital adjustment, verbal aggression, and physical aggression as longitudinal predictors of physical aggression in early marriage. Journal of Consulting and Clinical Psychology 73(1), 28-37.

Schwartz, J. P., Griffin, L. D., Russell, M. M., \& Frontaura-Duck, S. (2006). Prevention of dating violence on college campuses: An innovative program. Journal of College Counseling, 9, 90-96.

Skuja, K. \& Halford, W. K. (2004). Repeating the errors of our parents?: Parental violence in men's family of origin and conflict management in dating couples. Journal of Interpersonal Violence, 19, 623-638.

Snethen, G., \& Van Puymbroeck, M. (2008). Girls and physical aggression: causes, trends, and intervention guided by social learning theory. Aggression and Violent Behavior, 13, 346-354. 
Stephens, D. P., Fernandez, P. \& Richman, E. (2012). Ni pardo, ni prieto: The influence of parental skin color messaging on emerging adult Hispanic women's dating beliefs. Women \& Therapy: Special Issue on Latinas and Latin America, 35, 4-18.

Stets, J. E. (1990). Verbal and physical aggression in marriage. Journal of Marriage and the Family, 52, 501-514.

Straus, M. A., Hamby, S. L., Buncy-McCoy, S. \& Sugarman D. B. (1996). The revised Conflict Tactics Scale (CTS2): Development and preliminary psychometric data. Journal of Family Issues, 17, 283-316.

Straus, M. A. \& Sweet, S. (1992). Verbal/symbolic aggression in couples: Incidence rates and relationships to personal characteristics. Journal of Marriage and Family, 54, 346-357.

Thomas, V., Kafescioglu, N., \& Love, D. P. (2009). Evaluation of the adults and children together (Act) against violence training program with child care providers. Journal of Early Childhood and Infant Psychology, 5, 141-156.

Tomison, A., \& Tucci, J. (1997). Emotional abuse: The hidden form of maltreatment. Issues in Child Abuse Prevention, 8, 243-253.

Van Doorn, M. D., Branje, S. J., \& Meeus, W. H. (2007). Longitudinal transmission of conflict resolution styles from marital relationships to adolescent-parent relationships. Journal of Family Psychology, 21, 426-434.

Villaruel, A. M. (1998). Cultural influences on the sexual attitudes, beliefs, and norms of young Latina adolescents. Journal of the Society of Pediatric Nurses, 3, 69-79.

Weber, K., \& Patterson, B. R. (1997). The effects of maternal verbal aggression on the adult child's future romantic relationships. Communication Research Reports, 14, 221-230.

Wekerle, C. \& Wolfe, D. A. (1999). Dating violence in mid-adolescence: Theory, significance, and emerging prevention initiatives. Clinical Psychology Review, 19, 435-456.

White, L. (1999). Contagion in family affection: Mothers, fathers, and young adult children. Journal of Marriage and Family, 61, 284-294.

Winstok, Z. (2006). The why and what of intimate conflict: Effect of the partners' divergent perceptions on verbal aggression. Journal of Family Violence, 21, 461468.

Women's College Hospital. (1995). Canadian women's health test. Toronto. 
Youniss, J. \& Ketterlinus, R. D. (1987). Communication and connectedness in motherand father-adolescent relationships. Journal of Youth and Adolescence, 8, 265280. 


\section{APPENDICES}

Appendix A: Proposed Theoretical Model

Appendix B: Modified Version of the Conflict Tactics Scale

Appendix C: Modified Version of the Conflict in Adolescent Dating

Relationships Inventory

Appendix D: Demographic Information

Appendix E: Results of Analyses

Appendix F: Analyzed Model 
Appendix A: Proposed Theoretical Model of the Relationship between Interparental Verbal Aggression, Parent-Daughter Verbal Aggression, and Verbal Aggression in Female Emerging Adult College Students' Intimate Relationships

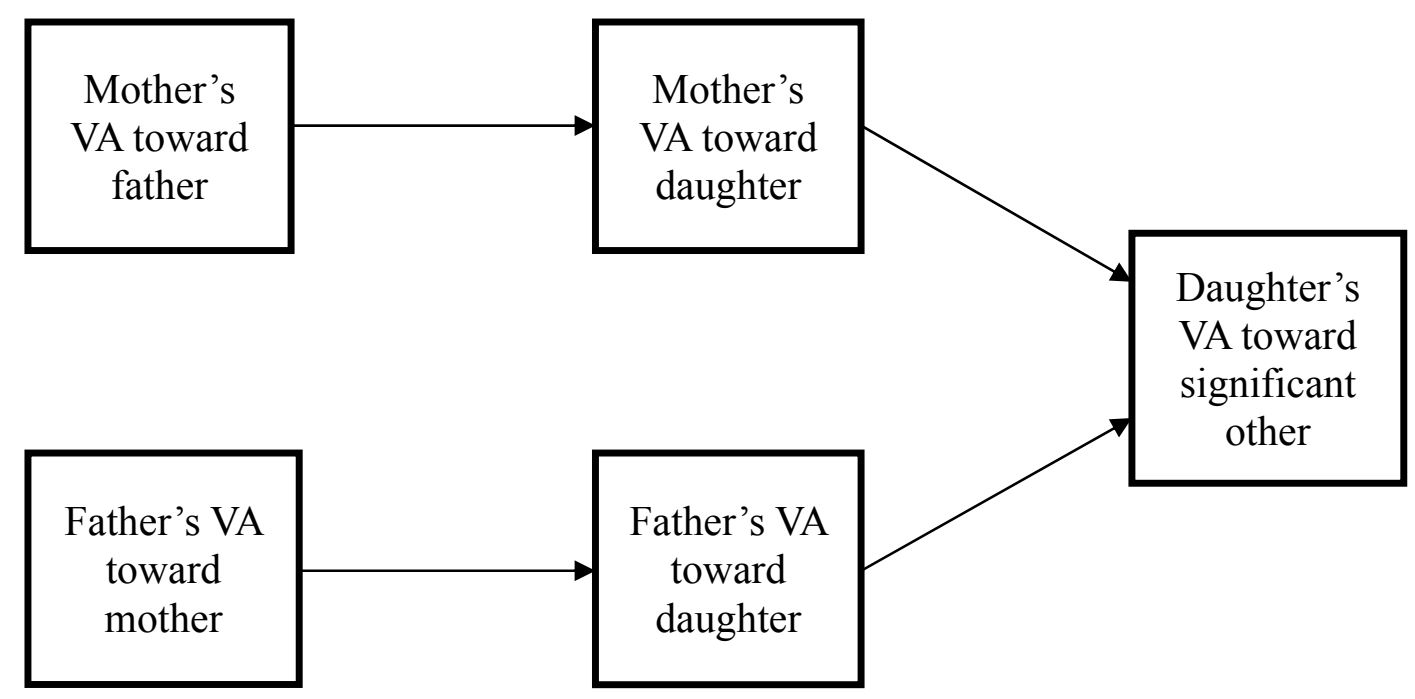




\section{CONFLICT WITH PARENTS}

Here is a list of things that you and your father and mother might have done when you had a conflict. Now taking all disagreements into account, we would like you to say how often you had done the things listed at any time during the last year. Answer by circling one of these numbers for each person.

$$
\begin{aligned}
& 1=\text { Never } \\
& 2=\text { Rarely } \\
& 3=\text { Sometimes } \\
& 4=\text { Often } \\
& 5=\text { Always }
\end{aligned}
$$

Father $\quad$ Me

Mother

$\mathrm{Me}$

1234

Yelled and/or insulted

$12345 \quad 12345$

1234

12345

Sulked and/or refused

$12345 \quad 12345$

to talk about it

1234

Stomped out of the room 123345

12345

1234

12345

Threw something

$12345 \quad 12345$

(but not at the other)

or smashed something

1234

Threatened to hit or

12345

12345

throw something at the

other 


\section{FATHER-MOTHER CONFLICT RESOLUTION}

We have the same list of things your father and mother might have done when they had a conflict. Now taking all disagreements into account (not just the most serious one), how often did they do the things listed at any time during the last year?

$$
\begin{aligned}
& 1=\text { Never } \\
& 2=\text { Rarely } \\
& 3=\text { Sometimes } \\
& 4=\text { Often } \\
& 5=\text { Always }
\end{aligned}
$$

Father

Mother

Yelled and/or insulted

$\begin{array}{lllll}1 & 2 & 3 & 4 & 5\end{array}$

$\begin{array}{lllll}1 & 2 & 3 & 4 & 5\end{array}$

Sulked and/or refused to talk about it

$\begin{array}{lllll}1 & 2 & 3 & 4 & 5\end{array}$

$\begin{array}{lllll}1 & 2 & 3 & 4 & 5\end{array}$

Stomped out of the room

$\begin{array}{lllll}1 & 2 & 3 & 4 & 5\end{array}$

$\begin{array}{lllll}1 & 2 & 3 & 4 & 5\end{array}$

Threw something (but not at the other)

or smashed something

$\begin{array}{lllll}1 & 2 & 3 & 4 & 5\end{array}$

$\begin{array}{lllll}1 & 2 & 3 & 4 & 5\end{array}$

Threatened to hit or throw something

at the other

$\begin{array}{lllll}1 & 2 & 3 & 4 & 5\end{array}$

$\begin{array}{lllll}1 & 2 & 3 & 4 & 5\end{array}$ 


\section{Appendix C: Modified Version of the Conflict in Adolescent Dating \\ Relationships Inventory}

The following questions ask you about things that may have happened to you with your boy/girlfriend while you were having an argument. Check the box that is your best estimate of how often these things have happened with your current or ex- boy/girlfriend in the past year. Please remember that all answers are confidential. As a guide use the following scale:

Never: this has never happened in your relationship

Seldom: this has happened only 1-2 times in your relationship

Sometimes: this has happened about 3-5 times in your relationship

Often: this has happened 6 times or more in your relationship

During a conflict or argument with my boy/ girlfriend in the past year:

Never Seldom Sometimes Often

I did something to make him/ her feel jealous.

$\mathrm{He} / \mathrm{she}$ did something to make me feel jealous.

I brought up something bad that he/ she had done in the past.

$\mathrm{He}$ / she brought up something bad that I had done in the past.

I said things just to make him/ her angry.

$\mathrm{He} /$ she said things just to make me angry.

I spoke to him/ her in a hostile or mean tone of voice.

$\mathrm{He} /$ she spoke to me in a hostile or mean tone of voice.

I insulted him/ her with put downs.

$\mathrm{He} /$ she insulted me with put-downs.

I ridiculed or made fun of him/ her in front of others.

$\mathrm{He} /$ she ridiculed or made fun of me in front of others. 
I kept track of who he/ she was with and where he/she was.

$\mathrm{He} /$ she kept track of who I was with and where I was.

I blamed him/ her for the problem.

$\mathrm{He} /$ she blamed me for the problem.

I accused him/ her of flirting with someone else.

$\mathrm{He} /$ she accused me of flirting with someone else

I threatened to end the relationship.

$\mathrm{He} /$ she threatened to end the relationship. 
Appendix D: Demographic Information

Table 1: Participants' Nationalities

\begin{tabular}{|l|c|c|}
\hline \multicolumn{1}{|c|}{ Country } & N & Percent \\
\hline Cuban & 229 & 38.2 \\
\hline American & 115 & 19.2 \\
\hline Colombian & 57 & 9.5 \\
\hline Puerto Rican & 41 & 6.8 \\
\hline Venezuelan & 30 & 5.0 \\
\hline Dominican & 21 & 3.5 \\
\hline Peruvian & 20 & 3.3 \\
\hline Nicaraguan & 19 & 3.2 \\
\hline Mexican & 13 & 2.2 \\
\hline Argentinean & 11 & 1.8 \\
\hline Ecuadorian & 9 & 1.5 \\
\hline Honduran & 8 & 1.3 \\
\hline Brazilian & 7 & 1.2 \\
\hline Other & 4 & .7 \\
\hline El Salvadorian & 3 & .5 \\
\hline Panamanian & 3 & .5 \\
\hline Spaniard & 2 & .3 \\
\hline Chilean & 2 & .3 \\
\hline Costa Rican & 2 & .3 \\
\hline Guatemalan & 1 & 100.0 \\
\hline Uruguayan & 599 & .2 \\
\hline Paraguayan & & \\
\hline Total & 1 & \\
\hline
\end{tabular}


Table 2: Current Place of Residence

\begin{tabular}{|l|c|c|}
\hline \multicolumn{1}{|c|}{ Residence } & $\underline{\mathbf{N}}$ & Percent \\
\hline Two parents & 324 & 54.1 \\
\hline Just my mother & 127 & 21.2 \\
\hline Other & 116 & 19.4 \\
\hline Just my father & 20 & 3.3 \\
\hline Grandparent(s) & 8 & 1.3 \\
\hline Aunt of Uncle & 3 & .5 \\
\hline Foster parent(s) & 1 & 100.0 \\
\hline Total & 599 & .2 \\
\hline
\end{tabular}

Table 3: Participants' Relationship Status at the Time of Data Collection

\begin{tabular}{|l|c|c|}
\hline \multicolumn{1}{|c|}{ Relationship Status } & $\underline{\mathbf{N}}$ & $\underline{\text { Percent }}$ \\
\hline Dating one person & 395 & 65.9 \\
\hline Not dating anyone & 183 & 30.6 \\
\hline Dating several people & 9 & 1.5 \\
\hline Dating two people & 6 & 1.0 \\
\hline Married & 6 & 1.0 \\
\hline Total & 599 & 100.0 \\
\hline
\end{tabular}

Appendix E: Results of Analyses

Table 4: Means and Standard Deviations of all Continuous Variables in the Model 


\begin{tabular}{|l|c|c|c|c|c|}
\hline & $\underline{\mathbf{N}}$ & $\underline{\text { Minimum }}$ & $\underline{\text { Maximum }}$ & $\underline{\text { Mean }}$ & $\begin{array}{r}\text { Std. } \\
\text { Deviation }\end{array}$ \\
\hline $\begin{array}{l}\text { Mother to } \\
\text { Father VA }\end{array}$ & 599 & 6 & 25 & 11.25 & 3.819 \\
\hline $\begin{array}{l}\text { Father to } \\
\text { Mother VA }\end{array}$ & 599 & 6 & 26 & 11.25 & 4.081 \\
\hline $\begin{array}{l}\text { Mother to } \\
\text { Participant } \\
\text { VA }\end{array}$ & 599 & 5 & 22 & 9.69 & 3.634 \\
\hline $\begin{array}{l}\text { Father to } \\
\text { Participant } \\
\text { VA }\end{array}$ & 599 & 5 & 21 & 8.53 & 3.381 \\
\hline $\begin{array}{l}\text { Participant to } \\
\text { SigOth VA }\end{array}$ & 599 & 10 & 37 & 20.06 & 6.218 \\
\hline
\end{tabular}


Table 5: Skewness and Kurtosis of all Continuous Variables in the Model

\begin{tabular}{|l|c|c|c|c|}
\hline \multirow{2}{*}{} & \multicolumn{2}{|c|}{ Skewness } & \multicolumn{2}{c|}{ Kurtosis } \\
\cline { 2 - 5 } & Statistic & Std. Error & Statistic & Std. Error \\
\hline Mother to Father VA & .619 & .100 & -.053 & .199 \\
Father to Mother VA & .784 & .100 & .421 & .199 \\
Mother to Participant VA & .765 & .100 & .304 & .199 \\
Father to Participant VA & .917 & .100 & .116 & .199 \\
Participant to SigOth VA & .397 & .100 & -.558 & .199 \\
\hline
\end{tabular}

Table 6: Fit Indices for Main Analysis

\begin{tabular}{|c|l|l|l|l|l|l|}
\hline & Chi Square $(\mathbf{d f}=\mathbf{3})$ & CFI & GFI & RMSEA & PCLOSE & SRMR \\
\hline Model & $3.088 p=.378$ & 1.000 & .998 & .007 & .817 & .0161 \\
\hline
\end{tabular}

Note. CFI is the Comparitive Fix Index, GFI is the Goodness of Fit Index, RMSEA is the Root Mean Square Error Approximation Test, PCLOSE is the p-value for the test of close fit for the RMSEA, and SRMR is the Standard Root Mean Square Residual. 
Appendix F: Analyzed Model

Figure 1: Relationship Between Parental Use of Verbal Aggression and Hispanic College Women's Use of Verbal Aggression in Romantic Relationships

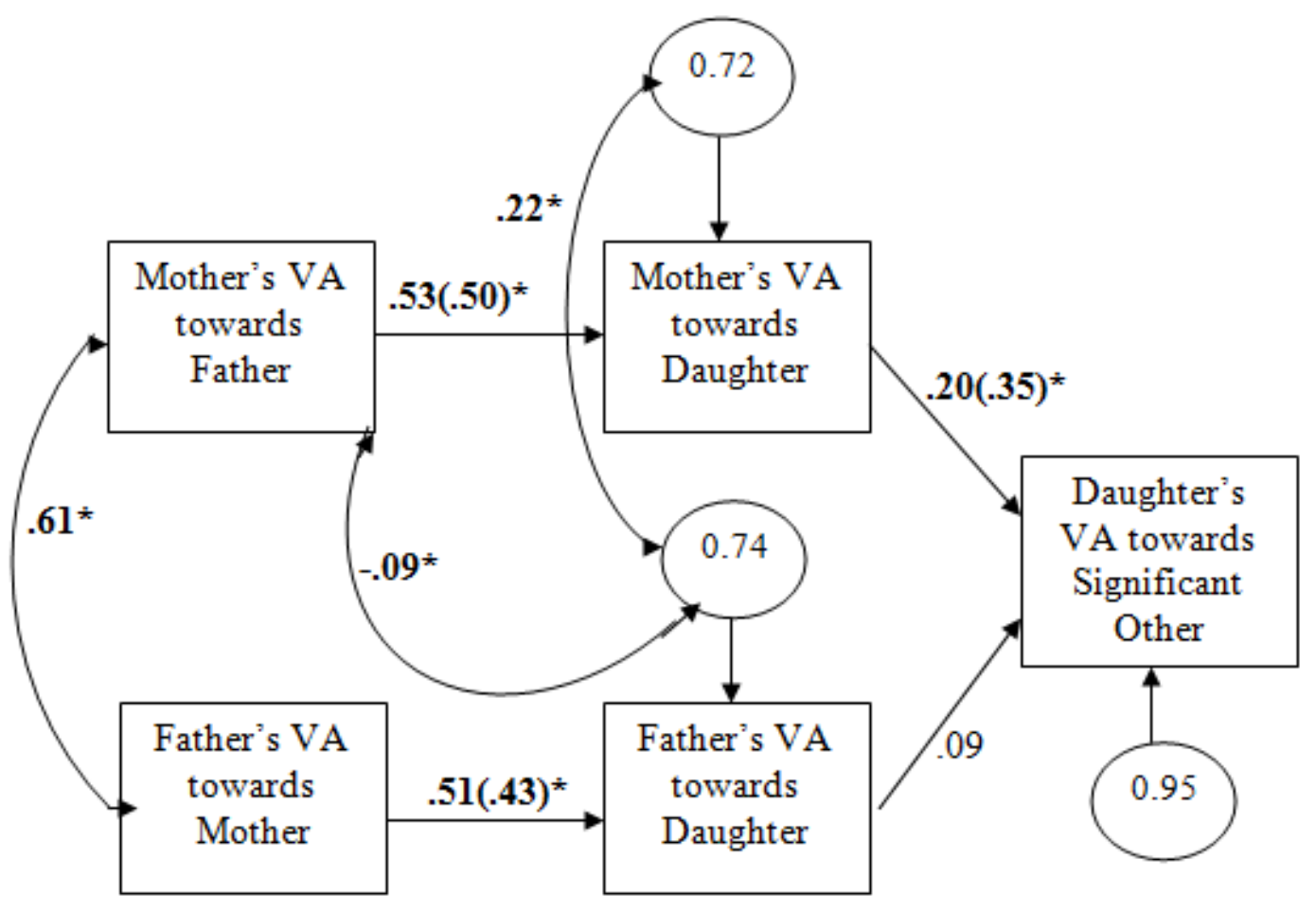

